\title{
AIDS: Setting a Feminist Agenda
}

\author{
Edited by Lesley Doyal, Jennie Naido, and Tamsin Wilton. Taylor \& Francis, Bristol, \\ England, 1994, 208 pp., \$75.00 (hardback), \$27.00 (paperback)
}

\author{
Shelly Grabe
}

Published online: 19 October 2010

(C) The Author(s) 2010. This article is published with open access at Springerlink.com

In this volume, the editors bring together writings aimed at a crucial link between feminism and HIV/AIDS work. The criticism offered of conventional HIV/AIDS work is that much of the attention to the AIDS epidemic has been rooted in the ideological agenda of Western scientific medicine which problematically reflects the hierarchical nature of a patriarchal medical profession that marginalizes the health needs of women. For this reason, the essays chosen for the edited volume discuss women's disempowerment from a gendered and sexualized lens that begins to explain why women have been marginalized in the discourse and work surrounding HIV/ AIDS. While these goals are lofty and inarguably imperative to include in the discourse, the essays do not always live up to the aims set forth in the introduction. Furthermore, the reader should beware that the analysis and statistics are dated and situated in the context of early 1990s United Kingdom.

The book is divided into four sections: (I) HIV/AIDS and women, (II) The Disputed Body, (III) Masculinities/Femininities, and (IV) Live Issues for a Feminist Agenda. The essays in the first section attempt to address the ways in which women are united in their vulnerabilities to HIV and AIDS. For example, women experience greater biological vulnerability to sexually transmitted diseases that is reinforced by cultural, social, and economic factors. As such, the essays address how the hierarchical nature of patriarchy adversely affects women's ability to advocate for and protect themselves, which negatively impacts their susceptibility to living with HIV/AIDS. The authors also highlight that the social factors that lead to the spread of HIV, as well as good models of practice for working with individuals affected by HIV, are different for women-

S. Grabe $(\bowtie)$

Department of Psychology, University of California, Santa Cruz,

1156 High St., Santa Cruz, CA 95064, USA

e-mail: sgrabe@ucsc.edu there is a sharp discussion of the documented male bias in access to quality care, the unique issues imposed by pregnancy and breastfeeding, and the ineptness of prevention programs riddled with gender bias (e.g., require women's trust in the faithfulness of male partners). Also in this section are simple facts about transmission aimed at myth-busting for the novice reader. Despite that, Section I is dated and repetitive, and many of the issues raised are still relevant today. In particular, problems related to the relative lack of control women have over their sexuality and reproductive care have not been resolved in the years since the publication of this book. ${ }^{1}$

In Section II (The Disputed Body), three essays address how normative objectification of the woman's body creates a context in which women's body health is at elevated risk due to the problem of estranging women from their bodies. In this section, the philosophical nature of women's bodies as a contested site of control and power, from which women's risk of HIV is elevated, is fleshed out. The idea of disembodied femininity - how femininity estranges women from their bodies by encouraging them at once to control and be preoccupied with the surface image of their bodies and how it appears to others and lack control and knowledge over how the same body-its desires, safety, and care are influenced by male control-is presented as a challenge to safe sex-having it and educating about it. These essays highlight the challenge in promoting safe sex by arguing that the sexual objectification of women's bodies in safe-sex educational material caters to the exact culture of objectification that originally put women's bodies at risk. If women continue to be led to believe that their body is an object for the desire of men, ensuring one's safety in

\footnotetext{
${ }^{1}$ Editor's note: When this book was sent out for review, the Editor mistakenly had read the year of publication as 2004, not 1994! Professor Grabe kindly reviewed the book nonetheless. Perhaps the reader in 2010 can reflect on whether or not the situation has changed 16 years on.
} 
sexual encounters may take lower priority over male pleasure. Ultimately, these sections highlight the role of the body as power in the prevention and treatment of AIDS.

There were only two essays in Section III (Masculinities/ Femininities). The first addressed the mental health needs of women with AIDS, making the argument that the social and medical construction of HIV as a health problem for men has direct implications for the mental health of women living with HIV. While this could be a compelling argument, I found the thesis only moderately supported and, furthermore, the topic has likely received considerable more attention in the past decade. The second essay addressed the power inherent in heterosexual masculinity through a discussion of young males' struggles to be "masculine" or, in other words, demonstrators of sexual prowess. While the empowerment of women surrounding issues of sexuality and femininity cannot be truly realized without addressing the challenges posed to both men and women as a result of masculinity, this essay did not seem to compliment the others in the volume very well. Indeed, the two essays in this section seemed to be placed together because they did not fit well any where else.

The final section (Live Issues for a Feminist Agenda) includes essays on specific groups of women: prostitutes, lesbians, women who have learning difficulties, and women who use drugs in the context of HIV/AIDS. Again, while a discussion of the risk and safety involved in these subgroups of women is important in the AIDS discourse, this material is dated and, in its narrow focus, does not lend to the major contribution of this book as a work that challenges how the hierarchical nature of patriarchy adversely affects women's ability to advocate for and protect themselves.

In sum, the citations and references to "present" research and prevalence rates would pose a dilemma for the reader interested in learning about the current state of feminist analysis in the context of the AIDS epidemic. As such, I would not recommend most essays in this book for a reader who is seeking a solid grounding in current issues. However, the theoretical analysis that situates women's bodies as "contested sites" is still relevant today and provides a timeless conceptual analysis of the body as a source of empowerment.

Open Access This article is distributed under the terms of the Creative Commons Attribution Noncommercial License which permits any noncommercial use, distribution, and reproduction in any medium, provided the original author(s) and source are credited. 